Tropical Journal of Pharmaceutical Research April 2016; 15 (4): 787-791

ISSN: $1596-5996$ (print); 1596-9827 (electronic)

(C) Pharmacotherapy Group, Faculty of Pharmacy, University of Benin, Benin City, 300001 Nigeria.

All rights reserved.

Available online at http://www.tjpr.org

Original Research Article

http://dx.doi.org/10.4314/tjpr.v15i4.17

\title{
Healing effect of Terminalia chebula Retz extract on second-degree burns in rats
}

\author{
Ping Meng ${ }^{1 \star}$, Shouguo $\mathrm{Ma}^{1}$ and Shuwen Huang ${ }^{2}$ \\ ${ }^{1}$ Department of Burn and Plastic Surgery, Zhangqiu Municipal People's Hospital, ${ }^{2}$ Department of Pediatrics, Zhangqiu City \\ People's Hospital, Ji'nan City, Shandong Province 250200, China
}

*For correspondence: Email: huangshuwen133494@163.com; Tel: +86 053183251203

\begin{abstract}
Purpose: To investigate the healing effect of Terminalia chebula Retz. Extract (TCRE) on seconddegree burns in rats.

Methods: Male Sprague Dawley (SD) rats, weighing 200 - $220 \mathrm{~g}$, were subjected to deep seconddegree skin burns by electrical scald instrument. The animals were divided into three groups as follows: (1) second-degree burns model (control) group, (2) burns model treated with $1 \%$ silver sulfadiazine (SSD) group, and (3) burns model treated with $100 \mathrm{mg} \cdot \mathrm{mL}^{-1}$ TCRE group. On days 3, 7 and 14 following the administration of the drug/extract, the wound area and histopathological changes in rat epidermis were evaluated for the various groups. The minimum inhibitory concentration (MIC) of TCRE on Staphyloccocus aureus, Pseudomonas aeruginosa and Escherichia coli were also assessed separately. Results: On day 14, the mean wound area of TCRE treatment group $\left(0.25 \pm 0.06 \mathrm{~cm}^{2}\right)$ was significantly smaller than that of the control rats $\left(2.71 \pm 0.20 \mathrm{~cm}^{2}, p<0.01\right)$. The histological results indicate that the inflammatory cells disappeared and were replaced by new granulation tissue in the group treated with $100 \mathrm{mg} \cdot \mathrm{mL}^{-1}$ TCRE by day 14 . Compared with SSD group rats, the inflammatory cells and fibroblast and granulation tissues of burnt rats treated with $100 \mathrm{mg} \cdot \mathrm{mL}^{-1}$ TCRE were same as those of rats that had no burns. The antibacterial results revealed that the MIC of TCRE on Staphyloccocus aureus, Pseudomonas aeruginosa and Escherichia coli was 3.13, 12.5 and $6.25 \mathrm{mg} \cdot \mathrm{mL}^{-1}$, respectively.

Conclusion: Terminalia chebula Retz. has potentials to be developed as an effective medicinal herb for the treatment of second-degree burns.
\end{abstract}

Keywords: Terminalia chebula, Second-degree burns, Burn wound, Healing, Granulation tissues, Fibroblast, Antibacterial, Inflammatory cells

Tropical Journal of Pharmaceutical Research is indexed by Science Citation Index (SciSearch), Scopus, International Pharmaceutical Abstract, Chemical Abstracts, Embase, Index Copernicus, EBSCO, African Index Medicus, JournalSeek, Journal Citation Reports/Science Edition, Directory of Open Access Journals (DOAJ), African Journal Online, Bioline International, Open-J-Gate and Pharmacy Abstracts

\section{INTRODUCTION}

Every year, millions of people suffer major disabilities or even death from burns, caused by hot water, flame and boiling oil. People suffer from burns due to domestic and industrial accidents, which along with enormous cost of treatment, cause mortality and considerable morbidity [1]. According to the World Health Organization (WHO), there were 300,000 deaths worldwide due to burns in 2012, with $96 \%$ of these deaths occurring in developing countries [2]. Burns are one of the health problems in modern societies associated with irreparable damage to patients and family relationships [3].

Currently, SSD is the most used topical treatment for burns due to its potent antimicrobial efficacy. However, it was found that silver gets absorbed systemically, posing problems on 
prolonged use and systemic complications such as neutropenia, methemoglobinemia and renal toxicity [4]. Therefore, finding more efficient agents with fewer side effects for treatment of burns has always been a concern of researchers.

Terminalia chebula Retz., a traditional Chinese medicinal herb, is widely distributed in southern China. The root of Terminalia chebula Retz. has been used in treatment of inflammation, infection, jaundice, skin burns and hyperlipemia in China and Japan [5]. Several studies have evaluated the antioxidant capacity of Terminalia chebula Retz. extract [6-7] and its anti-inflammatory activities, such as the inhibition of NF-kB [8]. In the present study, the healing effect of Terminalia chebula Retz. extract on deep second-degree burn wounds in rats was investigated.

\section{EXPERIMENTAL}

\section{Materials}

Herbal samples of Terminalia chebula Retz. were collected from Bozhou City, Anhui Province in China in May 2014. Taxonomic identification of the plant was performed by Prof $\mathrm{Ku} \mathrm{He}$ of Shandong University of Chinese Medicine in China. A voucher specimen (no. TCRE 201405027) was deposited in the Department of Pharmacy, Zhangqiu Municipal People's Hospital, China for future reference.

The powdered sample $(20 \mathrm{~g})$ was placed in a round bottom flask with $70 \%$ ethanol $(1: 8, \mathrm{w} / \mathrm{v})$ for reflux extraction at $80{ }^{\circ} \mathrm{C}$. It was extracted twice, $2 \mathrm{~h}$ for each, and the ethanol solvent removed with a rotary evaporator, and the remaining solution was concentrated into $200 \mathrm{~mL}$ volume as the experimental drug. The working concentration of TCRE was equivalent to 100 $\mathrm{mg} \cdot \mathrm{mL}^{-1}$ (extract weights/final volume).

\section{Animals and model preparation}

Male SD rats weighing 200-220 g were obtained from Shandong Center for Disease Control and Prevention, Jinan, Shandong. The rats had free access to feeds which were purchased from Guangxi Jiangda Feed Co. Ltd, China, and were allowed to acclimatize for at least one week before use. The animal experiment was approved by the Animal Care and Use Committee of Zhangqiu Municipal People's Hospital (approval reference no. 20131004) and was carried out in compliance with the Animal Welfare Act and the $\mathrm{NIH}$ guidelines $(\mathrm{NIH}$ publication No. 80-23, revised 1996).
Ethyl carbamate solution (20\%) was used for anesthetizing the rats after the rat hair was shaved off. The top of electrical scald instrument (Changhai Hospital of Second Military Medical University, China) was pressed upon the back skin with a certain force for $15 \mathrm{~s}$ at $75{ }^{\circ} \mathrm{C}$. In this way, the second-degree burn model was prepared.

\section{Experimental groups and treatments}

All rats were randomly divided into three groups of thirty-five rats each: second-degree burn model group, SSD-treated group and TCREtreated group. All the animals in the seconddegree burn model, SSD-treated and TCREtreated groups received the deep second-degree burn. SSD cream $(1 \%, w / w)$ was used as the standard drug.

In a preliminary study, the dose-response properties of TCRE and silver sulfadiazine were examined to determine the optimal dose, and the most effective in the wound healing was $0.3 \mathrm{~g}$ SSD or $1 \mathrm{~mL}$ TCRE per wound (data not shown). One $\mathrm{mL}$ of TCRE or $0.3 \mathrm{~g}$ of SSD was applied slowly with cotton bud to the burn wound area and extended slightly outside the wound area to ensure inclusion of the wound edges. The treatments were repeated twice daily for 14 days. The first application was done directly after the injury. The control group did not receive any treatment for 14 days. The wound remained exposed after the treatment.

\section{Measurement of mean wound area}

On days 3,7 and 14, following treatment, average wound areas of the control, SSD and TCRE group rats were measured. The wounds were photographed with a digital camera in order to calculate the wound surface areas (WSA) with Autocad software 2013 (Autodesk Co. Ltd.). The change in wound surface area in a given day $\left(W S A_{\text {day-x }}\right)$ was expressed as a percentage of the wound area on the second day ( $\left.\mathrm{WSA}_{\text {day-2}}\right)$ using Eq 1.

$W S A=\left\{\left(W A_{\text {day }-2}-W S A_{\text {day }-x}\right) / W S A_{\text {day }-2}\right\} 100 \ldots \ldots .(1)$

\section{Histological studies}

Wound skin tissue samples were taken, using a scalpel, from the control, SSD and TCRE groups on days 7 and 14 for histological observation. The skin tissues were fixed with $10 \%$ formalin. After fixation, the samples were embedded in paraffin, cut into $3 \mathrm{~mm}$ frozen sections with a cryostat microtome, and then stained with 
hematoxylin eosin reagent. The collagen fiber, inflammatory cell, blood vessel and granulation tissue of the skin tissues were examined under a microscope.

\section{Antibacterial test}

Agar dilution was used to determine the minimum inhibitory concentrations (MIC) of TCRE on Escherichia coli (ATCC23276), Staphyloccocus aureus (ATCC26542) and Pseudomonas aeruginosa (ATCC25338). The three bacteria were all diluted to $1.5 \times 10^{5}$ CFU. $\mathrm{mL}^{-1}$ with $0.9 \%$ sodium chloride solution. The experiment was repeated three times to determine the MIC.

\section{Statistical analysis}

The data are expressed as mean \pm SEM. Multiple group comparisons were performed using one-way analysis of variance (ANOVA) with SPSS 18.0 software followed by a Dunnett's test to detect intergroup differences. $P<0.05$ was considered statistically significant.

\section{RESULTS}

\section{Wound healing}

The wound area of burnt rats minished progressively when applied with SSD or 100 $\mathrm{mg} \cdot \mathrm{mL}^{-1}$ TCRE treatment. The wounds treated with TCRE healed more quickly than those of the control group. The average wound area of TCRE and SSD treatment groups healed more quickly than the control groups by day $14(p<0.01)$ (Figure 1), suggesting that both treatment probably accelerated the process of wound healing, hence, there was a significant reduction in wound area. Meanwhile, the mean wound area of burnt rats treated with SSD was significantly smaller than that of the model rats on day $14(p<$ 0.01 ).

\section{Histological features}

After the initial burning and elimination of necrotic tissue, a second-degree burn showing muscular and adipose tissues was formed, of which there were neither dermis nor epidermis and infection was absent. Histological findings of the wounded skin, treated with SSD and TCRE on day 7 and 14 are shown in Plate 1 . On day 0 , collagen fiber was necrotic, inflammatory cells infiltrated below the striated muscles and vascular engorgement and necrosis were seen in the burn skin of model rats. On day 7 , there was severe infiltration of inflammatory cells and some fibroblast and granulation tissues were found in the burnt skin of the control rats. The burnt skin of rats treated with SSD or TCRE showed inflammatory cells decreased significantly and fibroblast and granulation tissues grew rapidly. By day 14, inflammatory cells were still seen and some fibroblast and granulation tissues grew in the burnt skin of the control rats. The inflammatory cells disappeared and new granulation tissue, collagen fibers and epithelialization progressed very quickly in rats treated with SSD or TCRE.

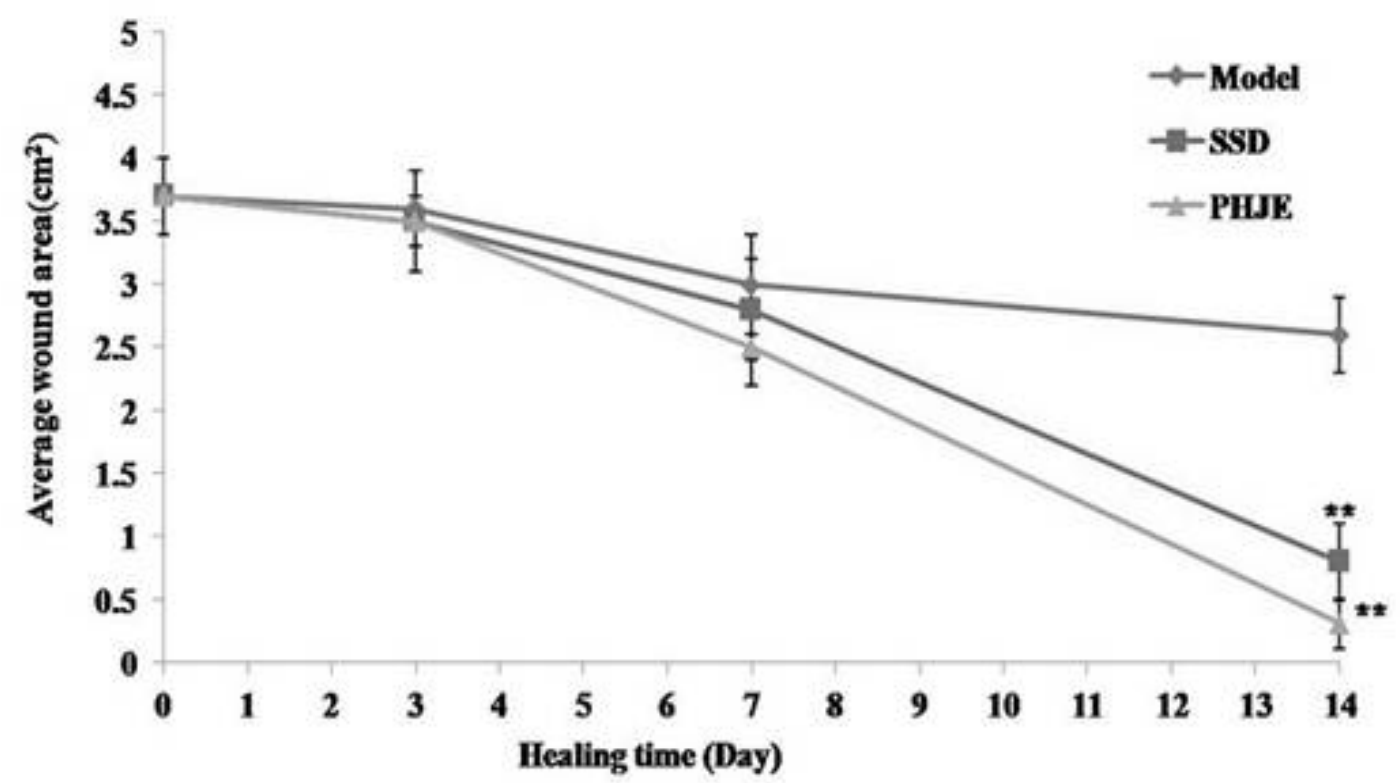

Figure 1: Evaluation of the wound area as a function of time $(n=10)$. The data are expressed as means \pm SEM. Differences between the model and the treated groups were significant $\left({ }^{*} p<0.05\right.$ and $\left.{ }^{* *} p<0.01\right)$ compared to the model 
Day 7

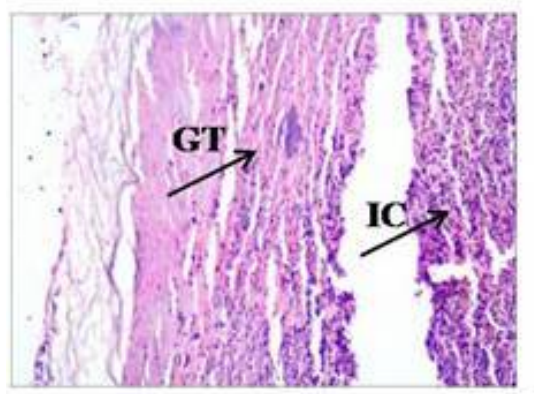

a

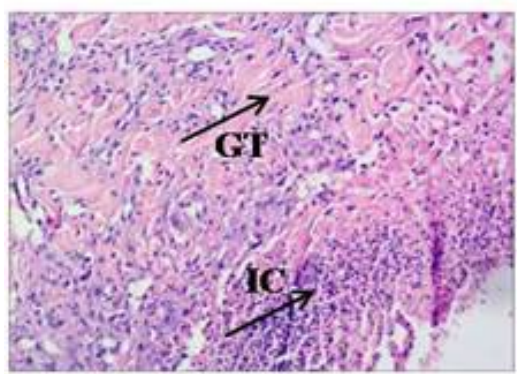

b

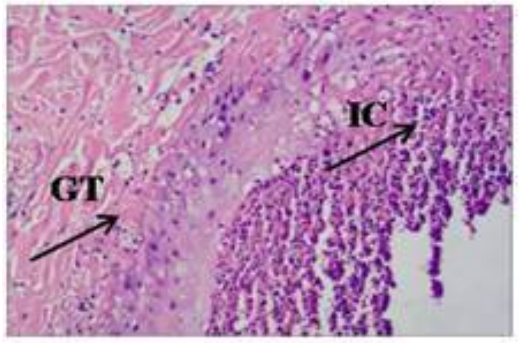

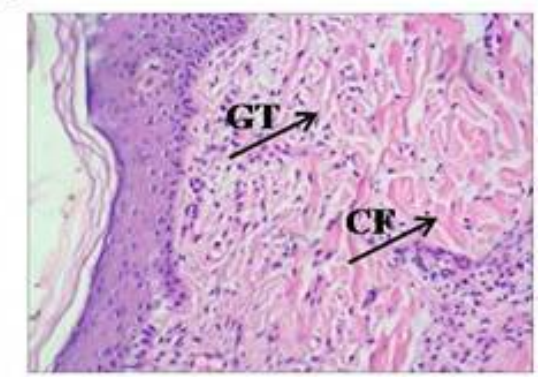

Day 14
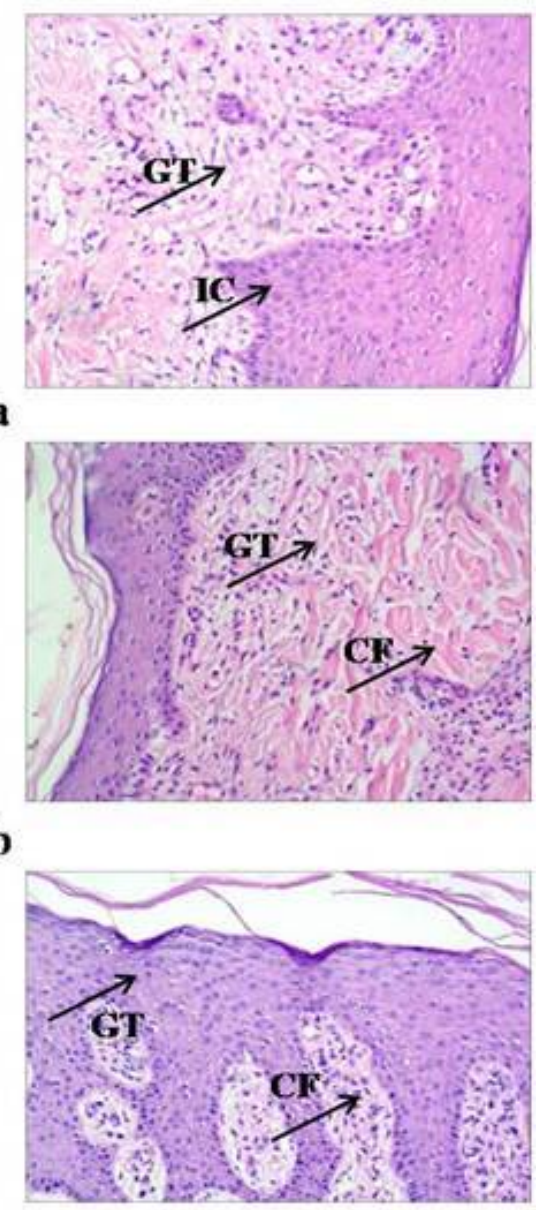

c

Plate 1: Skin pathomorphology of burn rats. (a) model, (b) SSD treatment, and (c) TCRE treatment on Day 7 and Day 14 respectively $(100 x)$. Note: $\mathrm{IC}=$ inflammatory cells, GT = granulation tissues, $\mathrm{CF}=$ collagen fibers

\section{Antibacterial test}

The MIC of TCRE on Staphyloccocus aureus, Pseudomonas aeruginosa and Escherichia coli were $4.8,19.2$ and $9.6 \mathrm{mg} \cdot \mathrm{mL}^{-1}$, respectively.

\section{DISCUSSION}

Thermal burn injury is still a major cause of death and disability in the world and its healing process is a challenge in modern medicine. Burns on human body may be treated by different methods depending on the extent and severity of the burn. SSD is bactericidal on a wide variety of bacteria, so it is commonly used to prevent and treat infections of second and third degree burns. Recent studies revealed that SSD ointment has positive effects on the proliferation of fibroblasts which are the main source of collagen and fibronectin [9]. However, current reports suggest that silver-based products show side effects and researchers are making efforts to seek for better topical antimicrobial products [10].

During the treatment of burn, the key method is to control bacterial infection. The common and main bacteria isolated from clinical burn patients were Staphylococcus aureus, Pseudomonas aeruginosa and Escherichia coli. SSD is the most used topical treatment for burn injury due to its anti-microbial efficacy. However, it has systemic complications such as neutropenia, methaemoglobinemia and renal toxicity.

Traditional Chinese medicine has the advantage of inhibiting bacterial growth with few side effects. It was reported that gallic acid was one constituent of Terminalia chebula Retz, and showed strong antibacterial activity [11]. Therefore, TCRE inhibited the bacterial growth of the burn wound effectively.

In recent years, there has been a growing interest in alternative medicines and natural 
medicinal products for the local treatment of wounds due to the high costs of traditional drug treatments [12]. Skin integrity is restored by a physiological process aimed at repairing the damaged tissues. The healing process proceeds in four phases: hemostasis, inflammation, proliferation and remodeling [13]. The time required for complete healing of deep seconddegree burns, without the application of specific therapeutic agents, can be three to six weeks or more and these burns will leave a scar tissue that may undergo hypertrophy and contract itself [14]. In our study, TCRE accelerated the scab of deep-degree burn wound and prevented infection effectively.

Burn wounds treated with TCRE recovered well by day 14. However, the wounds of the control group still showed severe inflammatory cell infiltration, but the epidermis of burn was healed.

\section{CONCLUSION}

These results reveal that Terminalia chebula Retz can accelerate the healing of seconddegree burns and has a strong antibacterial activity. The plant can potentially be developed into a product for burns treatment.

\section{REFERENCES}

1. Nacer KA, Mahlous $M$, Tahtat D. Evaluation of healing activity of PVA/chitosan hydrogels on deep second degree burn: pharmacological and toxicological tests. Burns 2013; 39: 98-104.

2. Kopp J, Wang GY, Horch RE. Ancient traditional Chinese medicine in burn treatment: a historical review. Burns 2003; 29: 473-478.

3. Edelman LS. Social and economic factors associated with the risk of burn injury. Burns 2007; 33: 958-965.
4. Shanmugasundaram N, Uma TS, Lakshmi TSR, Babu M. Efficiency of controlled topical delivery of silver sulfadiazine in infected burn wounds. J Biomed Mater Res A. 2009; 89: 472-482.

5. Peng W, Qin R, Li X. Botany, phytochemistry, pharmacology, and potential application of Polygonum cuspidatum Sieb.et Zucc.: A review. J Ethnopharmacol. 2013; 148: 729-745.

6. Masaki, H., Sakaki, S., Atsumi, T., Sakurai, H. Activeoxygen scavenging activity of plant extracts. Biol Pharm Bull 1995; 18: 162-166.

7. Hsu,C.Y., Chan, Y.P., Chang,J. Antioxidant activity of extract from Polygonum cuspidatum. Biol Res. 2007; 40: 13-21.

8. Eve, E.B., Phillip, G., James, L.H., Louise, W., Diane, K.H. Topical anti-inflammatory activity of Polygonum cuspidatum extract in the TPA model of mouse ear inflammation. J Inflamm 2008; 5: 1-4.

9. Coelho JM, Antoniolli AB, Nunese SD. Effects of silver sulfadiazine, ipêroxo (tabebuia avellanedae) extract and barbatimão (stryphnodendron adstringens) extract on cutaneous wound healing in rats. Rev. Col. Bras. Cir. 2010; 37: 45-51.

10. Burd A, Kwok CH, Hung SC, Chan HS, Gu H, Lam WK, Huang L. A comparative study of the cytotoxicity of silver-based dressings in monolayer cell, tissue explant, and animal models. Wound Repair Regen 2007; 15: 94104.

11. Aijuan L, Jixiang C, Weiming Z, Tao J, Xiaohua Z, Qianqun G. Antibacterial activity of gallic acid from the flowers of Rosa chinensis Jacq. against fish pathogens. Aquaculture Res. 2007; 38: 1110-1112.

12. Lee JA, Jeong HJ, Park HJ, Jeon S, Hong SU. Acupuncture accelerates wound healing in burnedinjured mice. Burns 2011; 37: 117-125.

13. Pazyar N, Yaghoobi R, Rafiee E, Mehrabian A, Feily A. Skin wound healing and phytomedicine: a review. Skin Pharmacol Physiol. 2014; 27: 303-310.

14. Johnson RM, Richard R. Partial-thickness burns: identification and management. Adv Skin Wound Care. 2003; 16: 178-187. 